\title{
A STUDY OF HOUSEFLY ESTERASES BY MEANS OF A SENSITIVE COLORIMETRIC METHOD
}

\author{
K. VAN ASPEREN \\ Laboratory for Research on Insecticides, Vondellaan 6, Utrecht, Netherlands
}

(Received 6 March 1962)

\begin{abstract}
Esterases in organophosphate susceptible and resistant houseflies were studied by means of a sensitive Gomori method. In susceptible flies the esterase activity to $\alpha$-naphthylacetate was found to be mainly due to the cholinesterase and an ali-esterase identical with that responsible for most of the activity to methylbutyrate. The latter enzyme is much less active to $\beta$-naphthylacetate than to $\alpha$-naphthylacetate.

The $K_{m}$ values of the cholinesterase for $\alpha$ - and $\beta$-naphthylacetate were $1.0 \times 10^{-4}$ and $2.3 \times 10^{-4}(\mathrm{M})$ respectively. The ali-esterase had a $K_{m}$ of approximately $10^{-4}(\mathrm{M})$ for $\alpha$-naphthylacetate.

The activity to $\alpha$-naphthylacetate of the cholinesterase was strongly, that of the ali-esterase only weakly $\mathrm{pH}$-dependent in the range from $\mathrm{pH} 6$ to 8 . Both enzymes were more active at higher $\mathrm{pH}$.

Eserine and diazoxon were used in inhibition experiments, acetylcholine and methylbutyrate in experiments on substrate competition. The $K_{m}$ value of the cholinesterase for acetylcholine was calculated as approximately $10^{-5}(\mathrm{M})$.

The addition of heat-inactivated homogenate strongly enhanced the ali-esterase activity to $\alpha$-naphthylacetate. It did so much more at low than at high concentrations of the active homogenate and thus caused the disappearance of the disproportionality initially observed between enzyme concentration and activity. This activation phenomenon was, to a lesser extent, also observed with $\beta$-naphthylacetate.

The ali-esterase activity to $\alpha$-naphthylacetate in homogenates of organophosphate resistant strains was only about 15 per cent of that found in homogenates of organophosphate susceptible strains. No significant differences between the activities in susceptible and resistant strains were found if $\beta$ naphthylacetate and indophenylacetate were used as substrates.

Agar-gel electrophoresis of the supernatants obtained by high-speed centrifugation of homogenates proved the presence of about seven electrophoretically different esterases that occurred in more or less strain-specific patterns.
\end{abstract}

\section{INTRODUCTION}

STUDIEs on the insecticidal action of organophosphorus (OP) compounds raised great interest in insect esterases, since (1) OP-compounds were found to cause strong inhibition of several esterases in a number of insects, (2) it seems well established that their insecticidal action is due to inhibition of the cholinesterase 
present in the nervous system, and (3) genetically modified esterases are capable of hydrolysing OP-compounds and thus confer resistance to these substances in several strains of houseflies. In 1953 Gomori published a very sensitive method for the quantitative assay of esterases in mammalian material based on the colorimetric estimation of naphthol that is produced by hydrolysis of naphthylesters. The present paper describes some results of a slightly modified Gomori method applied to the study of housefly esterases.

\section{MATERIALS AND METHODS}

Most experiments were done with a normal susceptible strain of houseflies $(S)$. Other strains used were the strains $C, D, F, G$, and $K$ (resistant to one or more organophosphates), that have been described in a previous publication (OPPENOORTH and VAN ASPEREN, 1961) and the strains $L$ highly resistant to DDT but susceptible to OP-compounds and $U_{2}$ highly resistant to DDT and $\mathrm{BHC}$ but susceptible to OP-compounds.

Enzyme preparations. These were obtained by homogenizing whole flies, fly heads, or other fly material in ice-cold distilled water by the aid of a cooled Waring blendor (small type). Dilutions of these homogenates were prepared as required. In some cases the homogenates were centrifuged and the supernatants used.

Substrate solutions. These solutions were prepared by diluting a stock solution of $\alpha$ - or $\beta$-naphthylacetate in acetone ( $0.03 \mathrm{M})$ in $0.04 \mathrm{M}$ phosphate buffer pH 7.

Diazoblue-sodium laurylsulphate solution. This solution was used for the estimation of the naphthols produced. It consisted of 2 parts of a $1 \%$ solution of diazoblue B (tetrazotized di-o anisidine, Edward Gurr, London, Colour Index 37235 ) and 5 parts of a $5 \%$ solution of Na-laurylsulphate (Servo, Delden-Holland). With this reagent $\alpha$-naphthol gives a strong blue colour (maximum absorption at $600 \mathrm{~m} \mu$ ), $\beta$-naphthol gives a strong red colour (maximum absorption at $555 \mathrm{~m} \mu$ ). Absorption was measured with a Beckman DU-spectrophotometer, using a $1 \mathrm{~cm}$ cell. Sodium laurylsulphate strongly enhanced the colour produced, possibly by solubilizing the naphthol-diazoblue complex and had the additional advantage of immediately stopping all esteratic activity.

The following is an example of a typical experiment: $5 \mathrm{ml}$ of substrate-solution $\left(3 \times 10^{-4} \mathrm{M} \alpha\right.$-naphthylacetate; containing $1 \%$ acetone and $0.04 \mathrm{M}$ phosphate buffer $\mathrm{pH} 7$ ) is mixed with $1 \mathrm{ml}$ of a homogenate (containing $0.025 \mathrm{fly} / \mathrm{ml}$ ). After 30 min incubation at $27^{\circ} \mathrm{C}, 1 \mathrm{ml}$ of the diazoblue laurylsulphate solution (DBLS) is added. A red colour immediately develops that quickly changes into a fairly stable blue colour, which is measured at $600 \mathrm{~m} \mu$.

Several modifications were introduced in this general set-up for studying different factors: $\beta$-naphthylacetate was occasionally used as substrate, substrate and enzyme concentrations were varied, inhibitors such as eserine and diazoxon were added, and $\mathrm{pH}$ was varied by using different buffer solutions, etc. 


\section{RESULTS}

\section{Calibration lines for $\alpha$-naphthol and $\beta$-naphthol}

These were obtained by reacting $6 \mathrm{ml}$ naphthol solution (in $1 \%$ acetone and $0.034 \mathrm{M}$ phosphate buffer $\mathrm{pH} 7$ ) with $1 \mathrm{ml} \mathrm{DBLS}$. The plots of naphthol concentration against optical density (O.D.) proved to be linear. The presence of 0.1 $\mu$ mole of $\alpha$-naphthol caused an O.D. of 0.559 (measured at $\lambda=600 \mathrm{~m} \mu$ ), $0 \cdot 1$ $\mu$ mole of $\beta$-naphthol gives O.D. $=0.598$ (at $\lambda=550 \mathrm{~m} \mu$ ).

\section{Enzyme concentration}

Experiments with flyhead homogenates showed the O.D. to be nearly proportional to the homogenate concentration (Fig. 1). It must be assumed that in

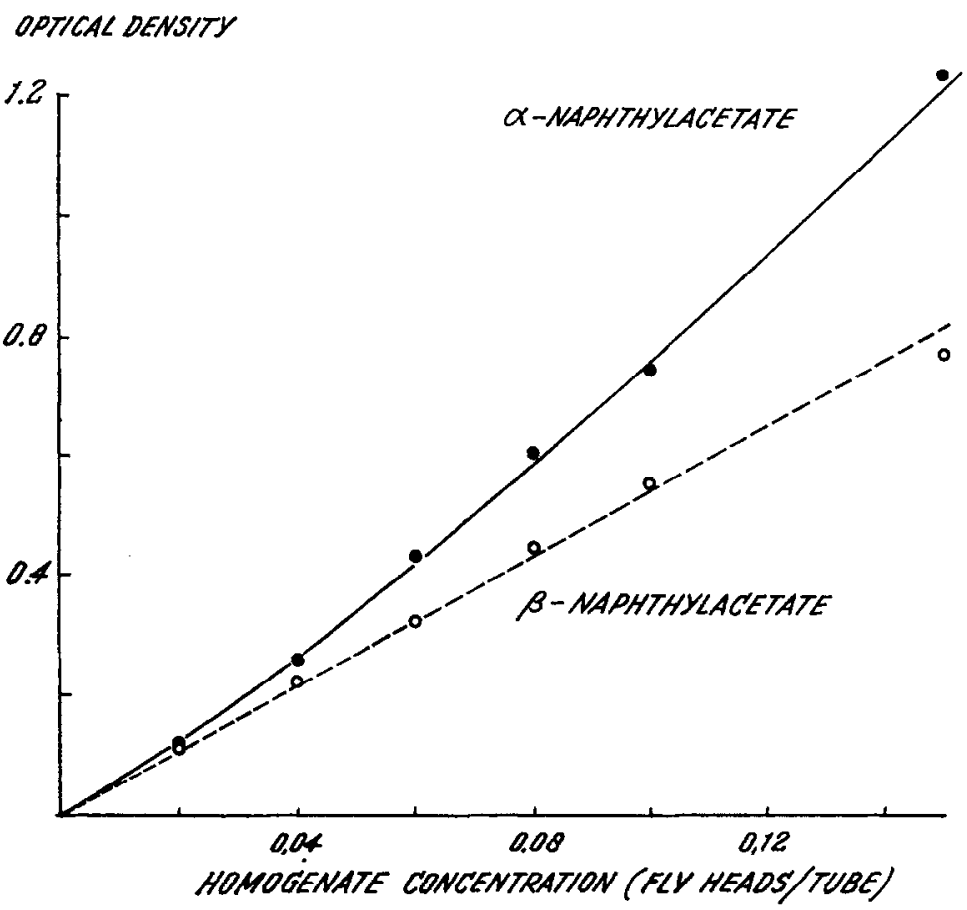

FIg. 1. The influence of homogenate concentration on flyhead activity. Incubation time $30 \mathrm{~min}$. Temp. $27^{\circ} \mathrm{C}$. Strain $S$. Substrate concentration $2.5 \times 10^{-4} \mathrm{M}$.

these experiments the esteratic activity was mostly due to the cholinesterase, since later experiments with whole-fly homogenates, in which cholinesterase was inhibited by the addition of eserine, showed a disproportionate increase of hydrolytic activity with increasing homogenate concentration (Fig. 2). This disproportionality as well as the striking difference between the strains $S$ and $C$ will be dealt with below. 


\section{Reaction time}

In most experiments homogenate and substrate were incubated for $30 \mathrm{~min}$. Some experiments were especially designed to study the relation between reaction

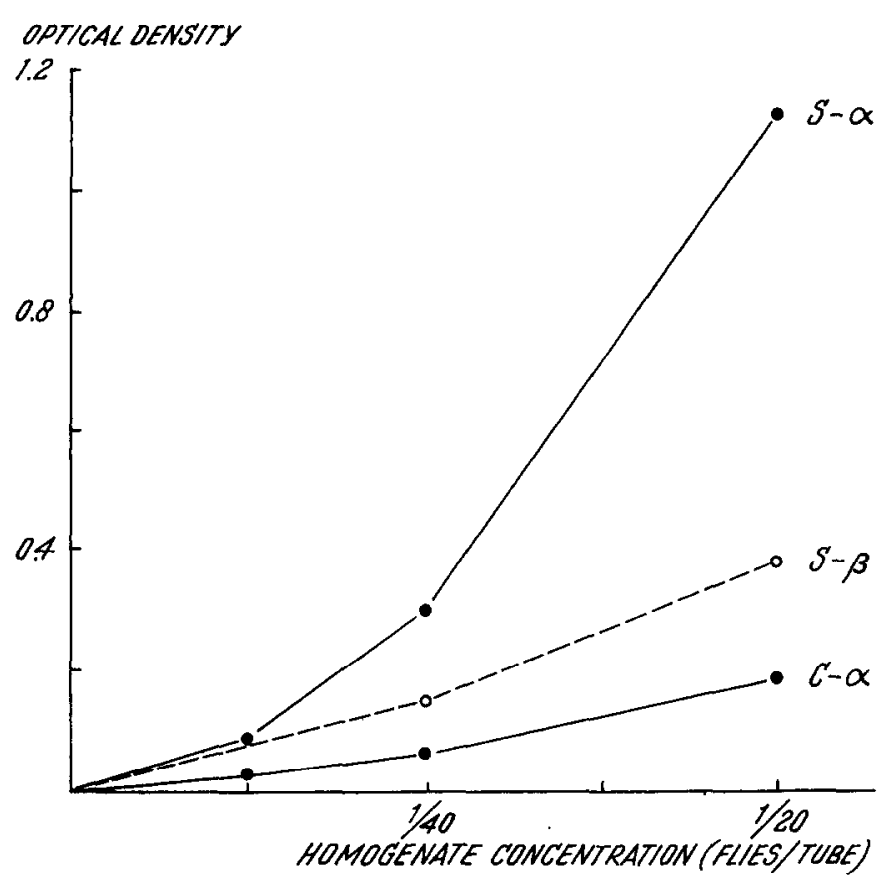

FIG. 2. The influence of homogenate concentration on whole-fly activity. Incubation time $30 \mathrm{~min}$. Temp. $27^{\circ} \mathrm{C}$. Substrate concentration $2.5 \times 10^{-4} \mathrm{M}$. Added $10^{-7} \mathrm{M}$ eserine. $S$ - $\alpha / \mathrm{Strain} S$ with $\alpha$-naphthylacetate. $S$ - $\beta /$ Strain $S$ with $\beta$-naphthylacetate. $C$ - $\alpha /$ Strain $C$ with $\alpha$-naphthylacetate.

time and rate of hydrolysis. Fig. 3 shows the results obtained with flyhead homogenates, Fig. 4 those obtained with a whole-fly homogenate. Eserine at $10^{-7} \mathrm{M}$ concentration was used for distinguishing cholinesterase activity and ali-esterase activity. The eserine-inhibitable (presumably cholinesterase) part of the activity was fairly constant for about $90 \mathrm{~min}$ in most cases. The non-inhibited part of the activity decreased with time, at least if $\alpha$-naphthylacetate was used as a substrate. The results also show that the cholinesterase is about equally active to both substrates, whereas the ali-esterase activity is much higher in the case of $\alpha$-naphthylacetate.

\section{Substrate concentration}

Fig. 5 shows Lineweaver-Burk plots of the results obtained with flyhead homogenates. The lines $A$ and $B$ refer to the eserine-inhibitable part of total hydrolysis, i.e. the cholinesterase. The $K_{m}$ values calculated from these plots are $1.0 \times 10^{-4}(\mathrm{M})$ for $\alpha$-naphthylacetate and $2.3 \times 10^{-4}(\mathrm{M})$ for $\beta$-naphthylacetate. 


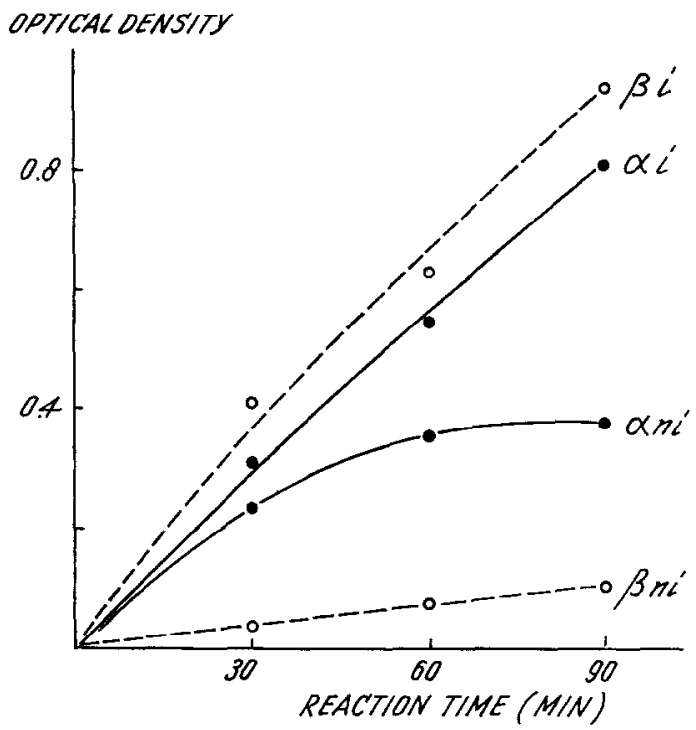

FIG. 3. The influence of reaction time on flyhead activity. Temp. $27^{\circ} \mathrm{C}$. Substrate concentration $2.5 \times 10^{-4} \mathrm{M}$. Strain $S$. Homogenate concentration 0.06 flyheads/tube. Eserine $10^{-7} \mathrm{M}$ added in one of two parallel experiments. $\alpha$ and $\beta$ refer to $\alpha$ - and $\beta$-naphthylacetate respectively, $i$ and $n i$ refer to the eserineinhibitable part and the non-eserine-inhibitable part of the activity respectively.

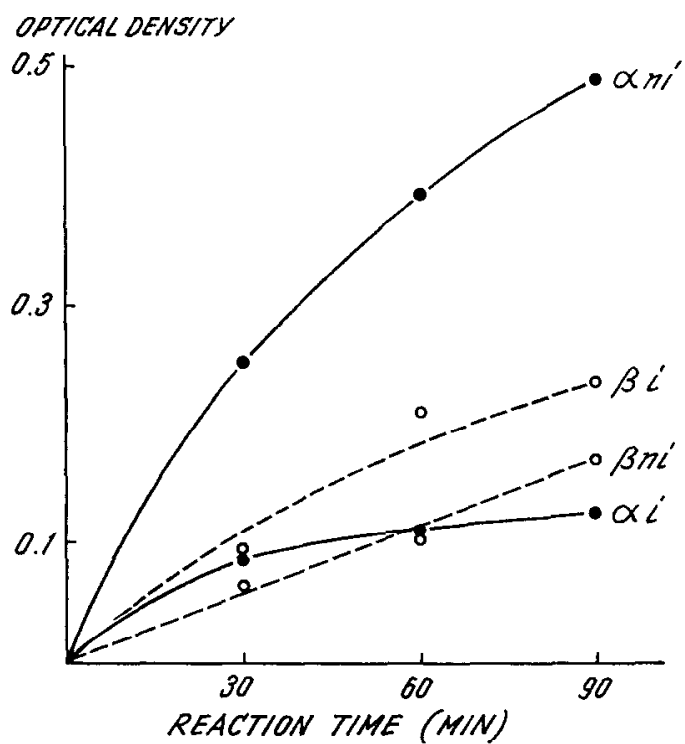

Fig. 4. The influence of reaction time on whole-fly activity. Homogenate concentration $\frac{1}{80}$ fly/tube. Further explanation: see Fig. 3. 
According to Dauterman et al. (1962), 2.5 flyheads contain $2 \mu \mu$ moles of cholinesterase. $V_{\max }$ can be derived from the intersection of the plot with the ordinate and converted to $\mu$ moles of substrate using the calibration lincs for $\alpha-$ and

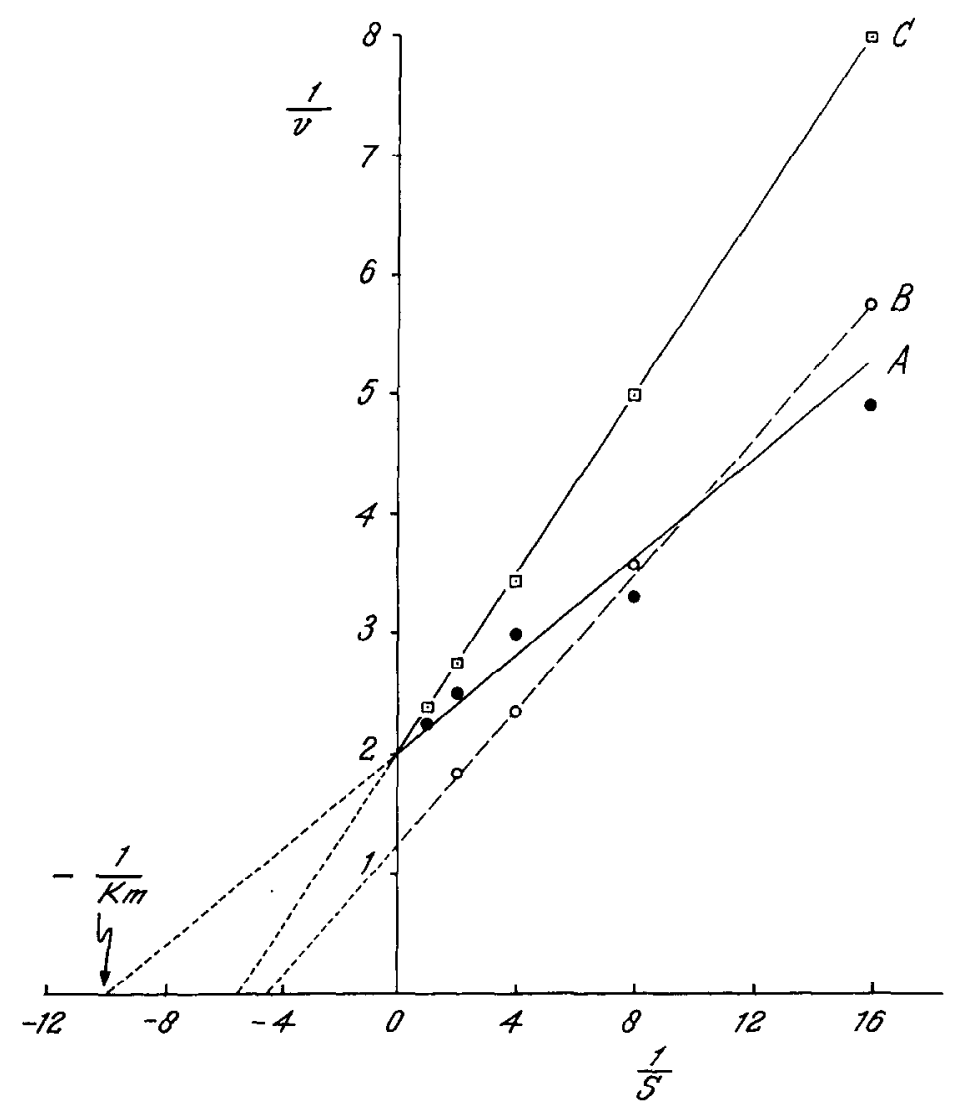

FIG. 5. The influence of substrate concentration on flyhead activity. Temp. $27^{\circ} \mathrm{C}$. Strain $S$. Incubation time $30 \mathrm{~min}$. Eserine $10^{-7} \mathrm{M}$ added in one of two parallel experiments. Homogenate concentration 0.08 flyhead/tube. Substrate concentration $(S)$ expressed in $\mathrm{mM} / 1$, , the rate of hydrolysis $(v)$ as O.D. after $30 \mathrm{~min}$. $A$, Cholinesterase with $\alpha$-naphthylacetate. $B$, Cholinesterase with $\beta$ naphthylacetate. $C$, Ali-esterase with $\alpha$-naphthylacetate.

$\beta$-naphthol. This permits the turnover-numbers (at $27^{\circ} \mathrm{C}$ ) for $\alpha$ - and $\beta$-naphthylacetate to be calculated as 50,000 and 80,000 respectively. Line $C$ represents the results obtained with the non-eserine-inhibited part of the activity to $\alpha$-naphthylacetate. For this reaction $K_{m}$ was found to be $1.85 \times 10^{-4}(\mathrm{M})$. Similar plots obtained for the non-eserine inhibited esterase activity of whole-fly homogenates were not linear and less reliable, probably partly due to the occurrence of more than one ali-esterase-like enzyme. The results, however, strongly point to one main ali-esterase with a $K_{m}$ of approximately $10^{-4}(\mathrm{M})$ for $\alpha$-naphthylacetate. 


\section{Hydrogen ion concentration}

The influence of $\mathrm{pH}$ on esterase activity of flyhead homogenate to $\alpha$-naphthylacetate was studied by variation of the phosphate buffer. Since at low $\mathrm{pH}$ the colour production with DBLS is very slow, the $\mathrm{pH}$ was corrected to 6.8 before the addition of the DBLS-reagent. Fig. 6 shows that the cholinesterase activity

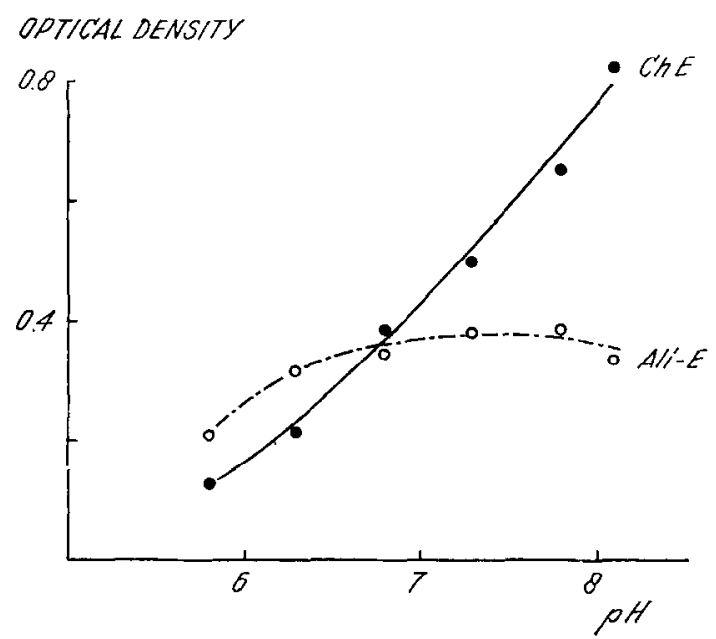

FIG. 6. The influence of $\mathrm{pH}$ on flyhead activity. Temp. $27^{\circ} \mathrm{C}$. Substrate: $2.5 \times 10^{-4}$. M $\alpha$-naphthylacetate. Strain $S$. Homogenate concentration 0.1 flyhead/tube. Eserine $10^{-7} \mathrm{M}$ added in one of two parallel experiments. $\mathrm{ChE}=$ Cholinesterase (eserine-inhibitable activity). Ali-E. = Ali-csterase (noneserine-inhibitable activity).

(eserine-inhibited) increases considerably from $\mathrm{pH} 5 \cdot 8$ to $\mathrm{pH} 8 \cdot 1$, whereas the ali-esterase activity (non-eserine-inhibited) is only little $\mathrm{pH}$-dependent. The latter result was completely confirmed by experiments on whole-fly homogenates.

\section{Inhibitors}

Fig. 7 plots the rate of $\alpha$-naphthylacetate hydrolysis by a flyhead homogenate in the presence of different concentrations of eserine. About 50 per cent of the total activity is readily inhibited by $10^{-8} \mathrm{M}$ eserine. Further increase of eserine concentration does not substantially decrease the hydrolytic rate. It is concluded that approximately half of the flyhead activity to $\alpha$-naphthylacetate is due to the cholinesterase, which is 50 per cent inhibited by ca. $10^{-9} \mathrm{M}$ and fully inhibited by $10^{-8} \mathrm{M}$ eserine. The addition of $10^{-7} \mathrm{M}$ eserine, as done in many experiments described in this paper, is believed to block the cholinesterase completely without interfering with the ali-esterase activity. In full agreement with results that were previously obtained with the Warburg method using methyl butyrate as a substrate (VAN ASPEREN and OPPENOORTH, 1960), it was found that the ali-esterase activity was readily inhibited by low concentrations of the organophosphate diazoxon (dicthyl-2-isopropyl-4-mcthyl-6-pyrimidinyl-phosphate). About 5.5 $\mu \mu$ moles of 
diazoxon per fly were required to obtain 50 per cent inhibition of eserinized whole-fly homogenates (Fig. 8). It was further found that heavy-metal salts strongly inhibit the esteratic activity to $\alpha$-naphthylacetate: 50 per cent inhibition of the ali-esterase activity resulted from the addition of $\mathrm{Hg}^{++}, \mathrm{Cu}^{++}$, and $\mathrm{Fe}^{+++}$ions at concentrations in the order of $10^{-7}, 10^{-6}$, and $10^{-5} \mathrm{M}$ respectively. The cholinesterase activity was also strongly inhibited by these ions, but somewhat less than the ali-esterase.

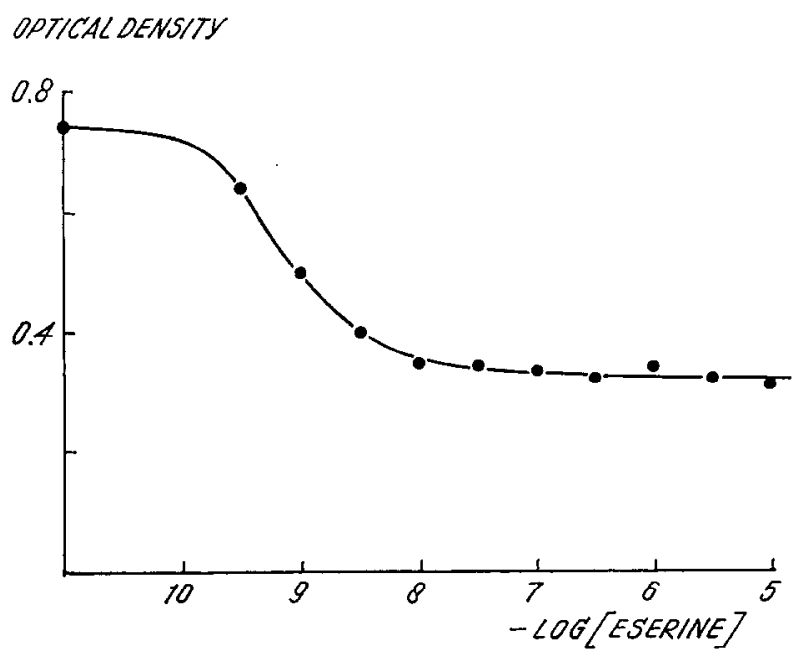

Fig. 7. Inhibition of flyhead activity by eserine. Temp. $27^{\circ} \mathrm{C}$. Substrate: $2.5 \times 10^{-4} \mathrm{M} \alpha$-naphthylacetate. Strain $S$. Homogenate concentration 0.1 flyhead/tube. Incubation time (enzyme-substrate) $30 \mathrm{~min}$. Eserine added to the homogenate immediately before the substrate.

\section{Substrate competition}

Acetylcholine strongly inhibited the cholinesterase activity to $\alpha$-naphthylacetate, e.g. if $\alpha$-naphthylacetate was used at $2.5 \times 10^{-4} \mathrm{M}$ concentration, 65 per cent inhibition was obtained with $5 \times 10^{-5} \mathrm{M}$ acetylcholine. Using DIXON and WeBB's formula for competitive inhibition (Drxon and WeBB, 1958, p. 92, formula IV.63), and the results of several experiments on inhibition by acetylcholine, the $K_{m}$ of the cholinesterase-acetylcholine complex was calculated to be ca. $10^{-5}(\mathrm{M})$. A more unexpected result was that the ali-esterase activity of flyhead homogenates also proved to be inhibited by acetylcholine, though at much higher concentrations of the latter: 50 per cent inhibition was obtained with ca. $10^{-1} \mathrm{M}$ acetylcholine. Whereas acetylcholine is a substrate of the cholinesterase and as such competes with $\alpha$-naphthylacetate for this enzyme, it seems unlikely that it is a substrate for the ali-esterase or, if so, the turnover number of acetylcholine by the aliesterase must be very low, since eserine-inhibited fly heads show only negligible hydrolytic activity to acetylcholine. 
Methylbutyrate inhibited the activity of eserinized whole-fly homogenates to $\alpha$-naphthylacetate: 50 per cent inhibition resulted from about $10^{-2} \mathrm{M}$. It seems probable, therefore, that a large part of the ali-esterase activity to $\alpha$-naphthylacetate is due to the ali-esterase that splits methylbutyrate. Further evidence for this will be produced below.

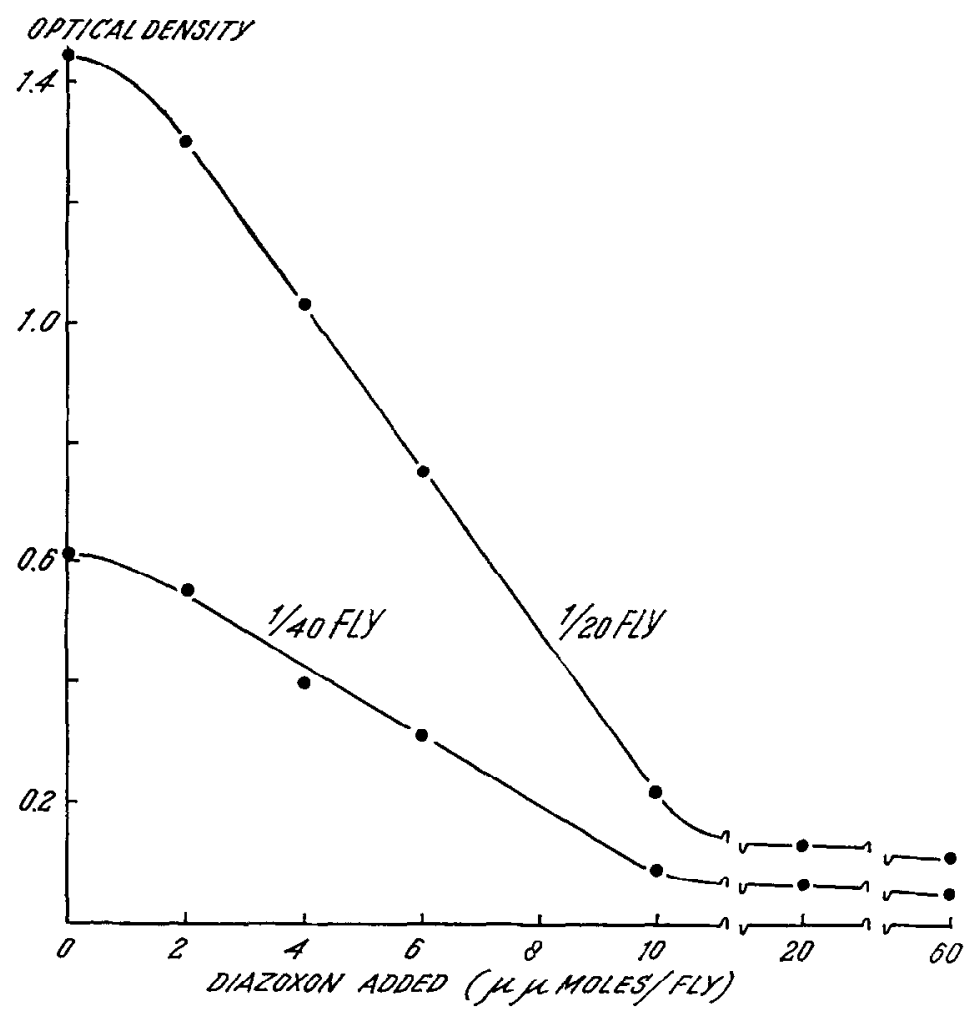

FIG. 8. Inhibition of whole-fly ali-esterase activity by diazoxon. $1 \mathrm{ml}$ of fly homogenate containing one fly was incubated with $1 \mathrm{ml}$ of diazoxon solution for $30 \mathrm{~min}$ at $27^{\circ} \mathrm{C}$. The reaction mixture was then $10 \times$ or $20 \times$ diluted and $1 \mathrm{ml}$, corresponding with $\frac{1}{20}$ or $\frac{1}{60}$ fly respectively, was added to $5 \mathrm{ml}$ of eserinized $\alpha$-naphthylacetate solution (in buffer $\mathrm{pH} 7$ ). After $30 \mathrm{~min}$ incubation at $27^{\circ} \mathrm{C} 1 \mathrm{ml}$ DBLS was added and optical density measured. Eserine concentration $10^{-7} \mathrm{M}$. Substrate concentration $2.5 \times 10^{-4}$ M. $1 \mu \mu$ mole $=10^{-12}$ mole.

\section{Activation by inactive homogenates}

The disproportionate increase of the hydrolytic rate with increasing homogenate concentration as shown in Fig. 2 suggested the concentration of some factor in the homogenates to be important in enhancing the activity of the ali-esterase. This was investigated' by keeping whole-fly homogenates at $70^{\circ} \mathrm{C}$ for $5 \mathrm{~min}$, which destroys all esterase activity, and adding small amounts of this denatured homogenate to the incubation mixture of fresh fly homogenate and naphthylacetate. 
Fig. 9 shows that even minute amounts of denatured homogenate strongly enhance the rate of hydrolysis, and Fig. 10 shows that the disproportionality nearly disappears if a sufficient amount of denatured homogenate is added for activation.

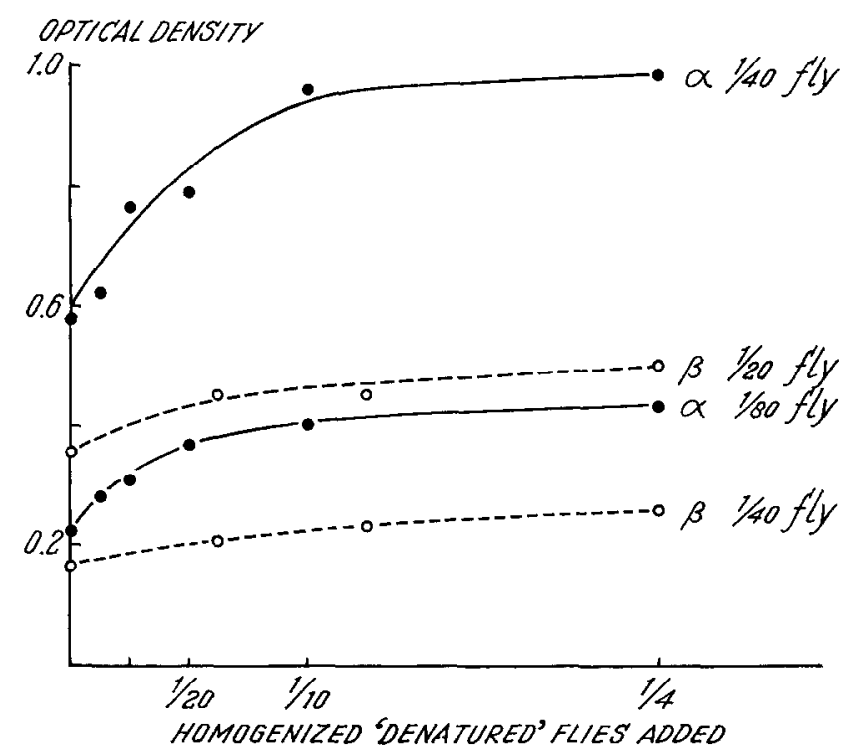

FIG. 9. Activation by inactive homogenates. A fly homogenate was kept at $70^{\circ} \mathrm{C}$ for $5 \mathrm{~min}$ ('denaturation'). After filtration through a loose plug of cotton-wool $1 \mathrm{ml}$ of diluted filtrate was added to $4 \mathrm{ml}$ of buffered naphthylacetate-eserine solution. $1 \mathrm{ml}$ of normal fly homogenate, containing the indicated amount of active fly material, was then added. Temp. $27^{\circ} \mathrm{C}$. Incubation time $30 \mathrm{~min}$. Substrate concentration $2.5 \times 10^{-4} \mathrm{M}$. Final eserine concentration $10^{-7} \mathrm{M}$. Strain $S$. $\alpha$ and $\beta$ refer to $\alpha$ - and $\beta$-naphthylacetate respectively. Blank values (in the absence of active homogenate) were subtracted.

Nothing definite can be said about the mechanism of this activation, but there is strong evidence from a number of experiments that the addition of denatured homogenate improves the proportionality of hydrolysis with time, thus indicating an improved stability of the enzyme.

About equal activation was obtained by the addition of homogenates that were denatured at $55,70,85$, and $100^{\circ} \mathrm{C}$, which proves that the activating factor is not very heat-labile. It was further shown that it could not easily be precipitated by centrifugation, the supernatants after $30 \mathrm{~min}$ centrifugation at $32,000 \mathrm{~g}$ still caused strong activation, although there were indications that this was less than with denatured whole-fly homogenates. An ultrafiltrate of such a supernatant also gave activation, but distinctly less than the supernatant itself. Heat-inactivated supernatants of $S$ - and $C$-homogenates caused equal activation of either $S$ - or $C$-supernatants. This proves that the difference in esterase activity between $S$ and $C$-flies, that will be described below, is not due to a difference in the amount or effect of 'activator'. It should be mentioned here that similar but quantitatively 
less activation was observed after addition of pure crystalline bovine albumin. It was optimal (ca. 50 per cent increase) in the presence of $1 \mathrm{mg}$ albumin per tube and became less if excess albumin was added. All this evidence does not permit much to be said about the chemical nature of the activating factor. Control experiments excluded the possibility that denatured homogenate or albumin simply enhanced the intensity of the colour produced by a given amount of $\alpha$-naphthol.

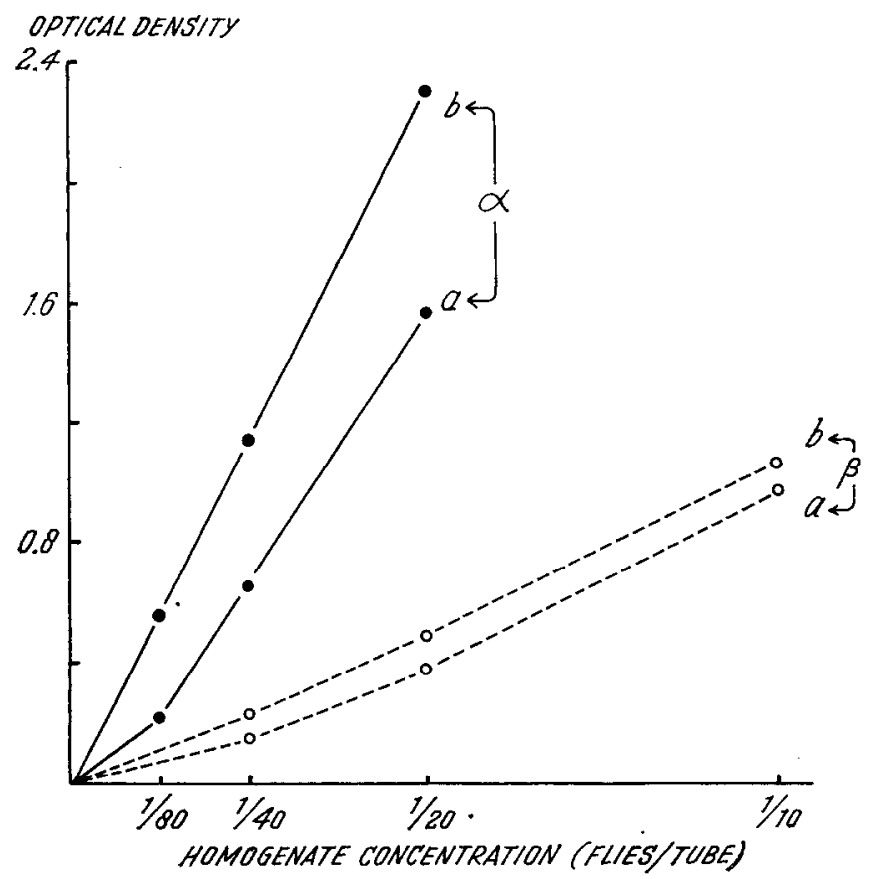

FIG. 10. Activation at different homogenate concentrations. Incubation time $30 \mathrm{~min}$. Temp. $27^{\circ} \mathrm{C}$. Substrate concentration $2.5 \times 10^{-4} \mathrm{M}$. Added $10^{-7} \mathrm{M}$ eserine. Strain $S . \alpha$ and $\beta$ refer to $\alpha$ - and $\beta$-naphthylacetate respectively. $a$ without addition of 'denatured' homogenate. $b$ with addition of 'denatured' homogenate ( $\left.\frac{1}{4} \mathrm{fly}\right)$.

\section{Distribution of esterase-activity}

Two experiments were performed in which a fly homogenate was successively centrifuged for $15 \mathrm{~min}$ at $1000,11,000$, and $32,000 \mathrm{~g}$. The ali-esterase activity of several dilutions was measured in the whole homogenate and in the three supernatants obtained. 'Table 1 clearly shows that the esterase-activity to $\alpha$-naphthylacetate gradually decreases with increasing speed of centrifugation: the supernatant obtained after $32,000 \mathrm{~g}$ shows only about one-third of the activity of the original homogenate. Ultracentrifugation at $100,000 \mathrm{~g}$ for $3 \mathrm{hr}$ in one case gave even much lower activity in the supernatant. Probably, therefore, most of the ali-esterase activity is due to particulate and a very small fraction only to soluble enzymes. It must be emphasized that the results of centrifugation experiments showed a rather large quantitative variation but all confirmed the above conclusion. 
Experiments with whole flies, fly heads, and fly bodies (decapitated flies) with and without addition of eserine showed that 60 per cent of cholinesterase activity and 20 per cent of ali-esterase activity to $\alpha$-naphthylacetate is contributed by the heads.

\section{TABLe 1 -Differential CENTRifugation}

Homogenate concentration during centrifugation $1 \mathrm{fly} / \mathrm{ml}$ (made up in distilled water). Dilutions $(10 \times, 20 \times, 40 \times, 80 \times)$ were made of homogenate and supernatants and $1 \mathrm{ml}$ used for assay by mixing with $5 \mathrm{ml}$ buffered, eserinized, $\alpha$-naphthylacetate solution. Temp. $27^{\circ} \mathrm{C}$. Substrate concentration $2.5 \times 10^{-4} \mathrm{M}$. Eserine concentration $10^{-7} \mathrm{M}$. Incubation time 30 min. Strain $S$.

\begin{tabular}{lllll}
\hline & \multicolumn{5}{c}{ Ali-esterase activity (O.D. $\times 1000)$} \\
\cline { 2 - 5 } 15 min centrifugation at & $\frac{1}{80}$ & $\frac{1}{40}$ & $\frac{1}{20}$ & $\frac{1}{10}$ \\
\hline Homogenate & 253 & 647 & 1625 & - \\
$3000 \mathrm{rev} / \mathrm{min}(1000 \mathrm{~g})$ & - & 474 & 1115 & 2260 \\
$10,000 \mathrm{rev} / \mathrm{min}(11,000 \mathrm{~g})$ & - & 285 & 718 & 1580 \\
$17,000 \mathrm{rev} / \mathrm{min}(32,000 \mathrm{~g})$ & - & 213 & 525 & 1420 \\
\hline
\end{tabular}

The esterase activities to $\alpha$-naphthylacetate of full-grown larvae, pupae, and adults were roughly equal. Female flies were more active than male flies, possibly due to their larger mean weight. Eggs, if compared on a weight basis, showed an activity of only about 10 per cent of that of adult flies.

\section{Esterase activity in organophosphate susceptible and resistant flies}

Table 2 shows the non-eserine-inhibitable esterase activities of homogenates of three OP-susceptible and five OP-resistant strains of houseflies. Included in this table are results obtained with the substrate indophenylacetate. The results show that, irrespective of whether activation by inactive denatured homogenate was applied, the activities to $\alpha$-naphthylacetate were much higher for OP-susceptible than for OP-resistant flies (mean act. susceptible: mean act. resistant $=8$ ). No such difference was found if $\beta$-naphthylacetate or indophenylacetate were used as substrates. Low esterase activity to $\alpha$-naphthylacetate (ca. 10 per cent of the activity in strain $S$ ) was also found in a strain $F_{a}$, obtained by repeatedly back-crossing strain $F$ with strain $S$ with continuous selection for low ali-esterase activity to methylbutyrate (OPPENOORTH, 1959). All this is strong evidence that the hydrolysis of methylbutyrate and that of $\alpha$-naphthylacetate by homogenates of susceptible flies are mainly due to one and the same enzyme. A large number of activity measurements (substrate $\alpha$-naphthylacetate) in single individuals of strain $S, C$, and $G$ and of $F_{1}$-generations of the crosses $S \times C$ and $S \times G$ showed that the values obtained with the OP-resistant strains $C$ and $G$ were invariably much lower than those obtained with strain $S$, whereas those of the $F_{1}$-flies were intermediate. 
'TABLE 2-ESTERASE ACTIVITY IN ORGANOPHOSPHATE SUSCEPTIBLE AND RESISTANT HOUSEFLIES

All activities are expressed as O.D. $\times 1000$. For conditions and explanation see below.

\begin{tabular}{|c|c|c|c|c|c|c|c|c|}
\hline & \multirow[b]{2}{*}{ Strain } & \multicolumn{4}{|c|}{$\begin{array}{c}\alpha \text {-Naphthylacetate } \\
\frac{1}{40} \text { fly per tube }\end{array}$} & \multicolumn{2}{|c|}{$\begin{array}{c}\beta \text {-Naphthylacetate } \\
\frac{1}{10} \text { fly per tube }\end{array}$} & \multirow{2}{*}{$\begin{array}{c}\begin{array}{c}\text { Indophenylacetate } \\
1 \text { fly per tube }\end{array} \\
\delta\end{array}$} \\
\hline & & 우 & q act. & శే & $\delta$ act. & $\sigma$ & of act. & \\
\hline $\begin{array}{l}\text { Organophosphate } \\
\text { susceptible }\end{array}$ & $\begin{array}{l}S \\
L \\
U_{2}\end{array}$ & $\begin{array}{l}962 \\
535 \\
902\end{array}$ & $\begin{array}{r}1450 \\
850 \\
1170\end{array}$ & $\begin{array}{l}680 \\
574 \\
625\end{array}$ & $\begin{array}{r}1045 \\
858 \\
1220\end{array}$ & $\begin{array}{l}720 \\
781 \\
940\end{array}$ & $\begin{array}{l}780 \\
964 \\
980\end{array}$ & $\begin{array}{l}569 \\
559 \\
714\end{array}$ \\
\hline $\begin{array}{l}\text { Organophosphate } \\
\text { resistant }\end{array}$ & $\begin{array}{l}C \\
G \\
F \\
D \\
K\end{array}$ & $\begin{array}{l}65 \\
64 \\
76 \\
73 \\
78\end{array}$ & $\begin{array}{l}139 \\
112 \\
197 \\
144 \\
180\end{array}$ & $\begin{array}{r}66 \\
74 \\
66 \\
100 \\
102\end{array}$ & $\begin{array}{l}130 \\
123 \\
137 \\
242 \\
205\end{array}$ & $\begin{array}{l}451 \\
648 \\
804 \\
748 \\
-\end{array}$ & $\begin{array}{l}571 \\
769 \\
812 \\
822 \\
-\end{array}$ & $\begin{array}{c}605 \\
396 \\
632 \\
845 \\
-\end{array}$ \\
\hline Factor Susc./Res. & & $11 \cdot 3$ & $7 \cdot 5$ & $7 \cdot 6$ & $6 \cdot 2$ & $1 \cdot 2$ & $1 \cdot 2$ & $1 \cdot 0$ \\
\hline
\end{tabular}

Conditions of assay in the case of $\alpha$ - and $\beta$-naphthylacetate: $\mathrm{T}=27^{\circ} \mathrm{C}$. Incubation time $30 \mathrm{~min}$. Substrate concentration $2.5 \times 10^{-4} \mathrm{M}$. Eserine concentration $10^{-7} \mathrm{M}$. Total volume (reaction mixture + DBLS) $=7 \mathrm{ml}$.

In most cases the activity was measured both without and with addition of 'denatured' homogenate ( $1 \mathrm{fly}$ ). The results of the latter experiments (with activation) are given in the columns headed by $f$ act. or $\delta^{x}$ act.

Conditions of assay in the case of indophenylacetate: $\mathrm{T}=27^{\circ} \mathrm{C}$. Incubation time $60 \mathrm{~min}$. The total reaction mixture is $5 \mathrm{ml}$, containing $\mathrm{fly}, 2.4 \times 10^{-4} \mathrm{M}$ indophenylacetate [ $\mathrm{N}$-( $4^{\prime}$-acetoxyphenyl)- $p$ quinone imine], $0.08 \mathrm{M}$ phosphate buffer $\mathrm{pH} 8$ and $10^{-7} \mathrm{M}$ eserine. Optical density (O.D.) caused by indophenol was measured at $625 \mathrm{~m} \mu(1 \mathrm{~cm}$ light path).

Factor Susc./Res. $=$ Mean activity susceptible strains : mean activity resistant strains.

\section{Agar-gel electrophoresis}

This was performed according to WIEME (1959) on microscope slides covered with agar gel. The conditions were as described by DaUTERMAN et al. (1962), except that the electrophoresis time was mostly $12 \mathrm{~min}$. The esterases were demonstrated by covering the agar gel on the slides with a few drops of $\alpha$-naphthylacetate solution $\left(3 \times 10^{-2} \mathrm{M}\right)$ in acetone, followed after $6 \mathrm{~min}$ by a few drops of $1 \%$ diazobluesolution in water. No laurylsulphate was added in this case. Brownish bands turned up at those sites where esterases were present due to the appearance of insoluble $\alpha$-naphthol-diazoblue precipitates. The plates could be preserved by drying between filter paper at $37^{\circ} \mathrm{C}$. The experiments were performed on the supernatants of concentrated homogenates (10 flies per ml) after $30 \mathrm{~min}$ centrifugation at $32,000 \mathrm{~g}$, which presumably removed most of the particles. The esterase-patterns obtained consisted of from four to seven different bands, which proves the occurrence in the supernatants of as many electrophoretically different esterases with hydrolytic activity on $\alpha$-naphthylacetate. Quite different but fairly 
reproducible patterns were obtained from the different strains used. Fig. 11 shows the patterns for the strains $C$ and $D$, that were the most characteristic ones so far obtained. No clear correlation of esterase pattern with resistance was observed, which is thought to be due to the particulate nature of the enzyme in the susceptible strains that is responsible for the remarkable difference described in the previous section. It is assumed that only soluble enzymes show up in the electrophoresis patterns.

Since only $1 \mu \mathrm{l}$ of supernatant is required for an expcriment, it was possible to obtain electrophoresis patterns of a single fly by homogenizing one fly in $100 \mu \mathrm{l}$ of water and centrifuging as described above. Also in this case the patterns consisted of several bands. Further work along these lines is in progress in our laboratory (VELTHUis and VAN ASPEREN, 1962).

\section{DISCUSSION}

The use of $\alpha$ - and $\beta$-naphthylacetate as substrates combined with a sensitive method for the estimation of naphthol by coupling with some diazo compound opens many possibilities for the study of esterases.

It was introduced by GOMORI for the quantitative assay of esterase activity in mammalian tissues and blood. However, it seems to be especially suitable for the study of esterases in insects and other small organisms, since only minute amounts of tissue or body fluid are required for a reliable measurement. The present paper shows that 10-100 $\mu \mathrm{g}$ of housefly tissue will be sufficient for assay of the esterase activity even if no special microtechnique is used. In our laboratory H. R. Smissaert (personal communication) could assay the esterase activity in individual adult two-spotted spider mites (Tetranychus urticae). A study of the distribution of esterases even in small insects will probably be possible.

The results reported here show that, under the conditions used, the hydrolysis of $\alpha$-naphthylacetate by homogenates of susceptible houseflies is mainly due to two enzymes, one being identical with the one splitting acetylcholine, i.e. the cholinesterase, and the other being identical with the ali-esterase that is responsible for most of the hydrolysis of methylbutyrate. The latter identity is based on two points of evidence: (a) methylbutyrate strongly inhibits the hydrolysis of $\alpha$-naphthylacetate, presumably by substrate competition and (b) the rate of hydrolysis is much lower in OP-resistant than in OP-susceptible flies, both to methylbutyrate and to $\alpha$-naphthylacetate. It must be assumed, therefore, that the genetical modification of this particular ali-esterase to organophosphate degrading enzymes in the OP-resistant flies not only strongly reduces its capacity to hydrolyse methylbutyrate and a number of other substrates (VAN ASPEREN and OPPENOORTH, 1959, 1960; OPPENOORTH and VAN ASPEREN, 1960, 1961) but also that to split $\alpha$-naphthylacetate.

No significant differences were found between the non-eserine-inhibitable activities of susceptible and resistant flies, if $\beta$-naphthylacetate and indophenylacetate were used as substrates. This is most easily explained by the assumption that the ali-esterase mentioned above has only little activity to these substrates, 


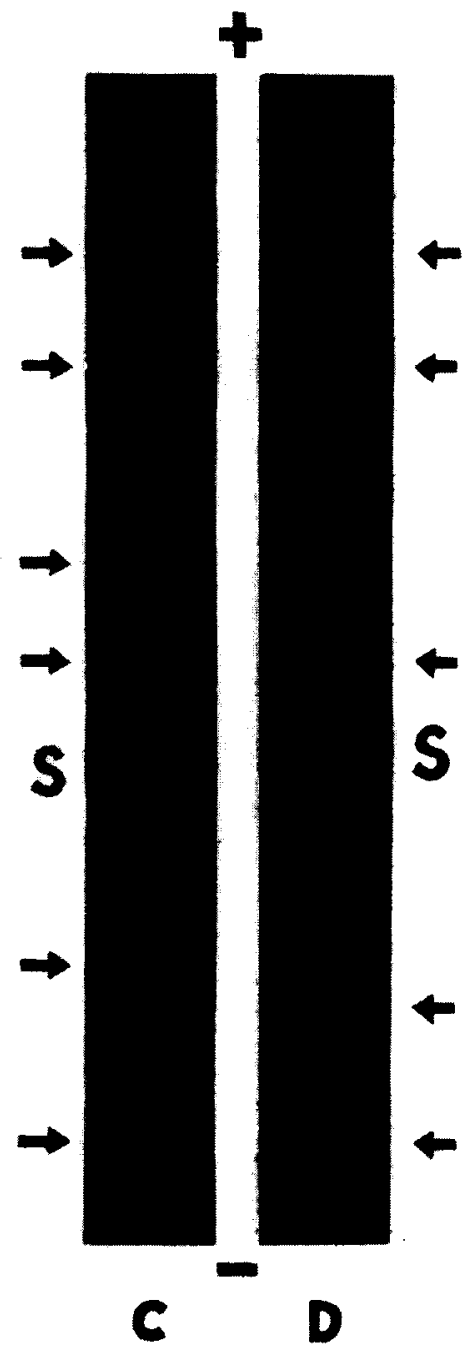

FIG. 11. Agar-gel electrophoresis of supernatants. The samples are introduced into the slit $S$. Two strains $(C$ and $D$ ) were used. Esterase-bands indicated by arrows. Illustration at actual size 3 . 
which in turn means that this ali-esterase has a remarkable specificity for the $\alpha$-isomer of the two naphthylacetates.

There can be no doubt that other ali-esterases are present in both OP-susceptible and resistant flies. Many of these seem to be present as soluble enzymes as shown by the patterns of several electrophoretically different esterases. The particulate nature of the main ali-esterase hydrolysing $\alpha$-naphthylacetate in the susceptible flies may be responsible for the lack of correlation between resistance and electrophoresis patterns. The strain specificity of the electrophoresis patterns is a remarkable fact and could possibly be considered as an extension of the species specificity of protein electrophoresis patterns in the haemolymph of a number of insects and spiders as described by vaN SANDE and Karcher (1960).

The measurement of non-eserine-inhibited esterase activity to $\alpha$-naphthylacetate and, to a much lesser degree, also that to $\beta$-naphthylacetate is complicated by the observed disproportionality between activity and homogenate concentration. Some years ago a similar disproportionality was found in several Warburg experiments on the hydrolysis of methylbutyrate if low homogenate concentrations (in the order of $0 \cdot 1-0.5 \mathrm{fly}$ per flask) were used. In this case, too, the addition of heat-inactivated homogenate caused activation at the lower homogenate concentrations and consequently the disappearance of the disproportionality. These results have not been published because they were not sufficiently reproducible. At the much lower homogenate concentrations used in the present method the phenomenon was invariably observed in the experiments on the non-eserine-inhibitable activity of both organophosphate susceptible and resistant flies. It must be assumed, therefore, that heat-denatured homogenate activates not only the main ali-esterase present in susceptible flies but also other ali-esterases, such as are found in both susceptible and resistant strains. The activation phenomenon was not observed in the case of the cholinesterase. So far, no definite conclusion can be drawn as to the mechanism of the activation or the nature of the activating factor.

It is believed that if due care is given to some pitfalls and peculiarities described in this paper, the use of naphthylacetates as substrates presents a highly sensitive method for studying insect esterases.

Acknowledgements-The author is much indebted to Mr. R. E. Ballieux (Medical Department of the University Hospital, Utrecht) for advice on electrophoresis techniques and to Mrs. Carla Hoefsmit-de Wilde, Mrs. Gay de Bie-Rike, Miss Anneke Talens, Mr. H. J. Muller, and Mr. A. WeYERs for skilful assistance.

\section{REFERENCES}

ASPEREN K. vaN and OPPENOORTh F. J. (1959) Organophosphate resistance and esterase activity in houseflies. Ent. exp. appl. 2, 48-57.

ASPEREN K. VAN and OPPENOORTH F. J. (1960) The interaction between organophosphorus insecticides and esterases in homogenates of organophosphate-susceptible and -resistant houseflies. Ent. exp. appl. 3, 68-83.

Dauterman W. C., Talens A., and Asperen K. van (1962) Partial purification and properties of flyhead cholinesterase. F. Ins. Physiol. 8, 1-14.

Dixon M. and Webs E. C. (1958) Enzymes. Longmans, London. 
Gomori G. (1953) Human esterases. F. Lab. clin. Med. 42, 445-453.

OPPENOORTH F. J. (1959) Genetics of resistance to organophosphorus compounds and low ali-esterase activity in the housefly. Ent. exp. appl. 2, 304-319.

OPPENOORTH F. J. and Asperen K. vaN (1960) Allelic genes in the housefly producing modified enzymes that cause organophosphate resistance. Science 132, 298-299.

OPPENOORTH F. J. and ASPEREN K. vaN (1961) The detoxication enzymes causing organophosphate resistance in the housefly; properties, inhibition, and the action of inhibitors as synergists. Ent. exp. appl. 4, 311-333.

SANDE M. vaN and KARCHER D. (1960) Species differentiation of insects by hemolymph electrophoresis. Science 131, 1103-1104.

VeLthUis H. H. W. and ASPEREN K. vaN (1962) In preparation.

Wieme R. J. (1959) An improved technique of agar-gel electrophoresis on microscope slides. Clin. chim. Acta 4, 317-321. 